\title{
Communication Networks used by Smallholder Livestock Farmers in Disease Outbreaks: Case Study of the Free State, South Africa
}

\author{
Christopher Ugochukwu Nwafor*1 \\ Ifeoma Chinyelu Nwafor ${ }^{2}$ \\ *manchrizzo@hotmail.com, \\ ${ }^{1}$ Department of Agriculture, Central University of Technology, South Africa
}

${ }^{2}$ Centre for Applied Food Sustainability and Biotechnology, Central University of Technology, South Africa

\begin{abstract}
Smallholder livestock farmers utilize their existing communication networks as information sources. This study explored these information sources, frequency of contacts and perceived usefulness of information from these sources. Using descriptive and correlation analysis, it categorized respondents according to total information score and explored the relationship between their scores and socio-economic characteristics. Findings show that $65 \%$ of farmers in the area scored a high reliance on fellow farmers and extension officials. Mass media sources such as radio and television scored low on perceived usefulness. The correlation coefficients for age (-0.228), farming experience $(0.183)$, extension visits $(0.002)$ and information contacts $(0.214)$ were significant $(\mathrm{p}<0.05)$. Level of education $(0.256)$, herd size $(0.067)$ and perceived usefulness of information contacts $(0.252)$ were also significant $(\mathrm{p}<0.01)$. Gender, household size, income, cooperative participation and access to financial services were not correlated to the total information scores of respondents. It was recommended that mass media sources in the area be supported by extension communication specialists to disseminate livestock-health related information.
\end{abstract}

Keywords: correlation, disease, extension, information-score, livestock, perceived-usefulness

\section{Introduction}

The smallholder livestock sector contributes to the economy and rural livelihoods in many African countries (Nyberg et al., 2015; Zougmore et al., 2016). In South Africa, the Department of Agriculture, Forestry and Fisheries (2018) estimates show the livestock sector contributing approximately $40 \%$ to agricultural incomes. Response to livestock health issues have improved due to its linkage to the economy, public health and food security. There is a recognition that inadequate control and prevention of livestock disease outbreaks may have huge negative economic and social impacts. The recognized connections among livestock health, public health, human nutrition and welfare outcomes has also resulted in the conceptualization of the one health approach (Thumbi et al., 2015). This tie between humans, animals and the surrounding environment is particularly close in developing countries, where poor farming communities raise animals (FAO 2019).

Economic loss from livestock diseases may be due to many reasons including additional expenses incured in treatment or prevention of the disease, production losses from unrealized potential or animal mortalities. Additional losses may be quantified under the reduction of income from earnings due to imposition of trade sanctions, a ban on livestock movement affecting traders, discontinuation of livestock auctions, large-scale cull of animals, livestock quarantine costs, reduced value of products, among many others. 
An effective response to outbreaks of livestock diseases require an appropriately designed and delivered message (Sellnow et al., 2017), which compels farmers to take applicable action to protect their livestock and farm enterprise. While the prevention and control of disease outbreaks ultimately depend on the adoption of best livestock-health management practices (Ritters et al., 2017), farmers' social referents influence their adoption of these requisite standards. Using communication networks that appeal to farmers' internal motivators hence elicits the desired behavior and increases their likelihood of adopting the identified health management intervention.

The African Swine Flu (ASF) virus disease and Rift Valley Fever (RVF) outbreaks have been documented in the Fezile-Dabi and Lejweleputswa municipalities of the Free State province, which is considered as one of the provinces severely affected by these diseases in South Africa (Mdlulwa \& Klein, 2015). A recent outbreak of the African swine fever in pigs was reported during May 2019 in the Free State (BFAP, 2019). Earlier the World Health Organization documented widespread Rift Valley Fever Virus (RVFV) infection affecting sheep, goats and cattle on farms within the Free State and a number of other provinces. According to official reports, approximately 78 farms reported laboratory-confirmed animal cases, with extensive livestock deaths (WHO, 2010). Meanwhile, anecdotal evidence indicated an even greater number of infected farms and clusters of local outbreaks among animals kept by smallholder livestock farmers (SA News, 2019).

\section{Problem Statement}

Farmer's communication networks play a vital role in their understanding of diseases, and preventive measures taken in response to the outbreak of livestock diseases. These measures are important for reducing both production losses and mortalities in their livestock, while improving herd health and productivity. The knowledge of communication networks among livestock farmers enable the dissemination of effective messaging for disease prevention and control, as well as undertaking significant interventions that meet local information needs. Moreover, existing local agricultural information systems need to be well understood so that they can be adequately utilized, managed and improved where necessary.

Though agricultural risk perception has received significant attention in the literature, few studies have explored the factors that influence the way farmers respond to particular livestock health risks, and how they obtain relevant information during an outbreak. This study accentuates the case of African Swine Flu Virus (ASFV) disease outbreaks, one of the most significant risks currently facing the smallholder pig farming sector, to explore these factors with a particular focus on the role of communication networks. Pig farming is considered as one of the few livelihood opportunities available to smallholder farmers within the affected areas in the Fezile-Dabi and Lejweleputswa districts.

Despite the multiplicity of information channels available to livestock farmers in the area, the communication networks utilized by smallholder livestock farmers in the affected districts is inadequately understood. Without an in-depth knowledge of communication networks used by smallholder livestock farmers in the area, messaging on measures for preventing the occurrence of notifiable diseases of livestock such as ASFV or RVF may be disseminated using poorly utilized information sources. This unfortunately results in farmers not being well-informed. Also an understanding on farmer's communication networks will justify the resources used and policies 
put in place for reaching livestock farmers with required information pertaining to their livestock enterprise. Muange et al. (2015) averred that while communication networks were an important avenue for the dissemination of information to farmers, the use of these networks were rarely investigated. This study therefore addressed the need to understand how livestock farmers within the area sourced livestock-health management information. Its objectives were to:

1. Assess the socio-economic characteristics of livestock farmers within the study area.

2. Identify sources of information relied on by farmers during the outbreak of diseases.

3. Measure the perceived usefulness of these information sources to livestock farmers.

4. Determine the relationship between socio-economic characteristics of respondents and total information scores.

\section{Conceptual framework}

The social network theory focuses on the role of social relationships in transmitting information (Liu et al., 2017), it describes social networks as nodes of individuals, as well as related systems that have commonalities or ties including values, ideas, contacts, kinship, culture, membership of organization, trade and other exchanges bearing the hallmark of human relationships. Social relations in this framework is seen in terms of nodes and ties, where the nodes represent individual actors and the ties correspond to the relationships or links between the actors. An analysis of the network shows relationships between people, and indicates how informal interactions either promote or hinder the dissemination of knowledge and information (Aidoo \& Freeman, 2016). Social networks are recognized as a form or source of social capital differing in composition, structure and size (Vishnu et al., 2019), and found in relationships maintained by individuals which can influence decisions (Kamau et al., 2018), or patterns of behavior. Communication networks describe regular patterns of interpersonal relationship through which information flows, and is also linked to a social network.

This study contributes to the literature related to local agricultural information systems, information sources and farmers communication networks. In the agricultural information systems conceptual framework, an information system is considered as a structure that includes people, technology and methods which are organized to collect, process, transmit and disseminate data or translates it into useful information (Demiryurek, 2010). The communication network is made up of inter-connected persons who are linked by a set of ties (Bogatti \& Halgin, 2011) along the flow of information, which also indicates how the system is structured. It describes a regular pattern of contacts between people which can be considered as information exchange in a specific social system. Communication networks are useful due to interaction and exchange of information among members of the system, and can be evaluated from the usefulness of information sources (Kumar et al., 2015).

\section{Methodology}

\section{Study area, sample frame and Data collection}

Study respondents were identified by stratified random sampling using the list of livestock farmers provided by the District office of the Department of Agrarian Reform. The list contained names of registered farmers residing in the two districts of Fezile-Dabi and Lejweleputswa. From each of these administrative districts an equal number of participants from each location were selected. The sample size for this study was calculated using the Raosoft sample volume 
calculation method based on a 5\% error rate, 95\% reliability level, and 50\% response distribution.

A pilot survey of 12 farmers was initially conducted to test the clarity, reliability, and validity of the questionnaire. The questionnaire was then revised and finalized in accordance with suggestions. The questionnaire consisted of four sections and 28 questions, and the internal consistency of answers given to the questions prepared according to the 4-point Likert scale was measured with reliability analysis. The Cronbach's $\alpha$, which is a numerical coefficient of reliability, was determined as $0.69,0.66$, and 0.74 , respectively.

The study applied the Total Information Score (TIS) technique to determine the information source(s) that respondents relied on for livestock health information, and calculated the perceived usefulness of such information sources in mitigating livestock health concerns. Frequency of information contact with different information sources was used to measure information score, while extent of contact and perceived usefulness of information also contributed to analyzing the information score. The total information score (TIS) combines the frequency of information contact with information sources and their usefulness into a variable (Demiryurek, 2010), reflecting not only the quantity but also the quality of the particular information contact.

Respondents were asked to specify utilized information source as well as frequency of contact within a specified period, selected to coincide with the reported outbreak of livestock disease. Weights were then assigned to each information source depending on the frequency of contacts. These weights ranged from 0 to 2 (with $0=$ no contact, $1=$ few contacts, $2=$ frequent contacts). The perceived degree of usefulness for each identified information source was also requested in relation to prevention and control of livestock diseases. Degree of usefulness of the information source was measured according to a four-point scale ranging from 0 to 3 (where $0=$ not useful, $1=$ slightly useful, $2=$ useful and $3=$ very useful). The degree of usefulness of information source was then weighted as follows, $0=0.0,1=0.25,2=0.50$, and $3=0.75$. We then correlated the degree of usefulness and frequency of contact to measure agreement among the two variables.

Total Information Score (TIS) for each information source was determined by multiplying the weighted number of contacts (FC) and degree of usefulness for the information source (IU), and may also be expressed as a percentage.

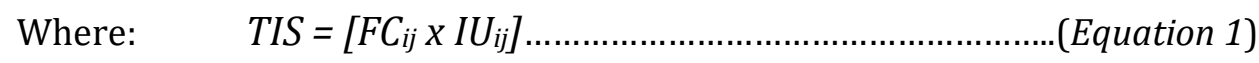

$F C_{i j}$ is the number of contacts with $j^{\text {th }}$ information channel to the $i^{\text {th }}$ farmer and $I U_{i j}$ is the usefulness of $j^{\text {th }}$ information channel to the $i^{\text {th }}$ farmer. Based on the total information scores, their average and standard deviations, each information source was then classified accordingly to be weak, moderate or strong. Furthermore, the relationship between socio-economic characteristics of respondents and Total Information Score was explored using a Pearson moment correlation coefficient.

\section{Results and Discussion}

Demographic characteristics of respondents 
Table 1 shows the personal characteristics of the survey respondents indicating that $54 \%$ were males and $46 \%$ female. Most of the respondents were aged 56 years and above, making up $60 \%$ of the total respondents. Only $6 \%$ of respondents were less than 36 years, with $33 \%$ of survey respondents in the 36-55 year bracket. Almost half of survey respondents (46\%) had between 5 and 7 persons in their household. Level of education among respondents varied, with $17 \%$ having no education, $36 \%$ had only a basic primary education, $20 \%$ attended a high school and $27 \%$ indicated a post high school attendance. The number of livestock owned by $33 \%$ of respondents was 50 or less, $36 \%$ and $31 \%$ of respondents had 51-100 animals and more than 100 animals respectively.

Table 1. Demographic characteristics of survey respondents

\begin{tabular}{|c|c|c|c|}
\hline Variable & & $\mathrm{N}=129$ & Percentage \\
\hline \multirow[b]{2}{*}{ Gender } & Female & 59 & 46 \\
\hline & Male & 70 & 54 \\
\hline \multirow[b]{3}{*}{ Age } & $<36$ years & 9 & 7 \\
\hline & $36-55$ years & 43 & 33 \\
\hline & $56+$ years & 77 & 60 \\
\hline \multirow[b]{3}{*}{ Household size } & $<5$ & 35 & 27 \\
\hline & $5-7$ & 59 & 46 \\
\hline & $>7$ & 35 & 27 \\
\hline \multirow[b]{4}{*}{ Education } & None & 22 & 17 \\
\hline & Primary & 47 & 36 \\
\hline & High School & 25 & 20 \\
\hline & Post High School & 35 & 27 \\
\hline \multirow[b]{3}{*}{ Herd size } & 50 or less & 43 & 33 \\
\hline & $51-100$ & 46 & 36 \\
\hline & More than 100 & 40 & 31 \\
\hline
\end{tabular}

The data reveals that there were more male livestock farmers than females within the study area, with many of them at least fifty-six years old. The prevalence of older male livestock farmers have been reported in different studies on communal livestock production in South Africa (Goni et al. 2018; Mthi et al., 2018). Large household sizes comprising five or more persons are also common in many rural communities across South Africa. Levels of education vary and more rural dwellers especially farmers have only completed a primary education. This agrees with the reported limited education among many smallholder farmers in the study area (Myeni et al., 2019). The herd size among respondents was also reflective of the number of livestock kept by smallholder rural farmers.

\section{Information sources used}

Livestock farmers seek out different credible and reliable sources of information in the event of disease outbreak. The most commonly used sources of information include peers, veterinary technicians or extension staff from government departments, radio and television programmes and even knowledgeable livestock traders and family members. Table 2 lists the information sources used by respondents during the livestock disease outbreak, showing that farmer-to- 
farmer contacts as well as extension officials were the main sources of livestock health-related information. Radio was also used as an information source, followed by family members and television ranked in the order shown.

Table 2. Information sources used by respondents for livestock diseases

\begin{tabular}{|c|c|c|c|c|}
\hline Information Sources & Rank & Score & Mean & SD \\
\hline Other farmers & 1 & 645 & 14.33 & 1.53 \\
\hline Extension officials & 2 & 196 & 5.02 & 1.32 \\
\hline Radio & 3 & 105 & 4.90 & 1.22 \\
\hline Family members & 4 & 74 & 4.56 & 1.26 \\
\hline Television & 5 & 41 & 3.72 & 1.51 \\
\hline
\end{tabular}

Source: Researchers computation from survey 2019

Peer networks have been reported as a highly effective information source which also influences the information-seeking behavior among farmers (Crawford et al., 2015, Nwafor et al., 2020). The importance of these personal relationships among farmers in information transfer has been noted by Sagor and Becker (2014) who indicated that peer interaction was also as an important learning tool. The role of extension is important for information dissemination to livestock farmers especially during an outbreak, and different sources have reported the reliance of farmers on extension officials. Though Chikaire et al. (2011) admitted the responsibility of extension officials to provide information to farmers, Adisa (2015) questioned the competence of some extension officials in animal health management issues. This probably contributed to the call by Katikati and Fourie (2019) for properly coordinated livestock-health extension programmes driven by trained and knowledgeable specialists.

Radio broadcasts are a veritable means for disseminating information, and Girma et al. (2017) highlighted its importance due to possible wide coverage especially among rural communities where a majority have access to radio in the household (Adamides \& Stylianou, 2018; Balan \& Norman, 2012). This finding regarding the importance of radio for information dissemination to rural farmers is however at variance with Lamontagne-Godwin et al. (2018) who reported the rare use of radio by respondents from their study. Family members and television were however, ranked low as sources of information during a livestock disease outbreak.

With several available sources of information, farmers will seek out those sources that are knowledgeable with specific reference to livestock diseases. This might explain why family members were ranked lowly in this instance. Also, Freeman and Mubichi (2017) have posited that certain characteristics of television explains why access is often limited, and despite its presence in many homes contributed little as a source of livestock-health information during the disease outbreak.

\section{Usefulness of information sources}

The realization that not all information sources are credible nor provide reliable information has resulted in concepts such as perceived usefulness acquiring particular significance. Farmers' perception of the usefulness of information sources and frequency of contact was used to determine their total information scores which is presented in Table 3, and it shows that farmer's 
colleagues and extension officials scored highest. These sources are followed by family members and mass media sources i.e. radio and television.

Table 3. Total information scores of respondents

\begin{tabular}{|c|c|c|c|c|c|c|c|}
\hline Sources used & $\mathrm{N}=129$ & $\begin{array}{c}\text { Freq. } \\
\text { (Month) }\end{array}$ & Weight & Total & $\begin{array}{c}\text { Perceived } \\
\text { usefulness }\end{array}$ & Weight & $\begin{array}{c}\text { Total } \\
\text { Information } \\
\text { Score }\end{array}$ \\
\hline Other farmers & 45 & 15 & 2 & 30 & 3 & 0.75 & 67.5 \\
\hline Extension officials & 39 & 8 & 3 & 24 & 4 & 1.00 & 96.0 \\
\hline Radio & 21 & 5 & 3 & 15 & 2 & 0.50 & 15.0 \\
\hline Family members & 15 & 25 & 2 & 50 & 1 & 0.75 & 37.5 \\
\hline Television & 9 & 20 & 2 & 40 & 1 & 0.50 & 20.0 \\
\hline
\end{tabular}

Source: Researcher's computation from survey 2019

Other farmers and extension officials have also been reported as a major information source among farmers (Modirwa, 2019; Olajide, 2011), which provide opportunities for extension practitioners to utilize peer-to-peer learning. From their study, Kumar et al. (2015) also identified other farmers and extension officials as belonging to a high-scoring group for information source usefulness among farmers. Radio and television sources were scored low which underlines their poor perceived usefulness. The role of mass media in disseminating agricultural information is noted (Ani et al., 2015; Ritter et al., 2017), however some studies have also averred their ineffectiveness (Javaid, 2017). Low total information scores obtained by mass media sources of information, including radio and television, is an indication of the need to provide targeted information related to livestock health especially during periods of disease outbreaks. Farmers are however known to utilize different sources of information, and Brhane et al. (2017) established the inadequacy of any single source.

The total information scores obtained for identified sources were categorized as shown in Table 4 into low, medium and high, based on the score range. The high category range from 50 up to 100 and included other farmers and extension officials, medium category ranged between 25 and less than 50 to include family members, and the low category scored less than 25 with radio and television included.

Table 4. Category based on TIS among respondents

\begin{tabular}{|c|c|c|c|c|}
\hline TIS category & Score range & $\begin{array}{c}\% \\
\text { respondents }\end{array}$ & Mean & SD \\
\hline Low & Less than 25 & 23 & \multirow{2}{*}{34} & 27.97 \\
\hline Medium & 25 and $<50$ & 12 & & \\
\hline High & 50 and more & 65 & \\
\hline
\end{tabular}

Source: Researcher's compilation from survey 2019

Sixty-five percent of respondents had total information scores in the high category, while twelve percent and twenty-three percent of respondents had score categories of medium and low respectively. This shows that the information sources categorized under high (other farmers and extension officials) were perceived by majority of respondents to be most useful in providing livestock-health related information. 


\section{Relationship between socio-economic characteristics and information score}

Access to livestock health information and the perceived importance of information received by farmers may depend on their socio-economic features. Information access and quality captured as total information score is an important dependent variable in the prevention and control of livestock diseases, and may be influenced positively or negatively by various personal characteristics of the farmer such as gender, age, level of education, herd size, farming experience, participation in cooperatives, or access to extension and other services. These independent variables presented in Table 5 were correlated with the total information scores of respondents.

Table 5. Correlation of TIS with respondents' socio-economic characteristics

\begin{tabular}{lcc}
\hline Independent Variables & Coefficient $(\mathrm{r})$ & Significance \\
\hline Sex & -0.033 & 0.069 \\
Age & $-0.228^{*}$ & 0.021 \\
Education & $0.256^{* *}$ & 0.010 \\
Household size & 0.314 & 0.557 \\
Livestock number & $0.067^{* *}$ & 0.005 \\
Farming experience & $0.183^{*}$ & 0.036 \\
Income & -0.124 & 0.237 \\
Cooperative participation & -0.092 & 0.065 \\
Extension visits & $0.002^{*}$ & 0.024 \\
Financial services & -0.145 & 0.198 \\
Information contacts & $0.214^{*}$ & 0.041 \\
Usefulness of information & $0.252^{* *}$ & 0.002 \\
\hline ** Significant correlation at 0.01 level, ${ }^{*}$ significant correlation at 0.05 level. \\
Source: Field survey data 2019. &
\end{tabular}

Gender difference was not found to correlate with total information score of respondents and was not significant in this study, Lamontagne-Godwin et al. (2018) however, reported from their study that preferences in accessing information sources were different between male and female farmers. There was a significant negative correlation $(-0.228)$ between age and total information score $(\mathrm{p}<0.05)$, an indication that age affects information contacts and perceived usefulness. Motiang and Webb (2015) also reported on the reliance on few information contacts among older cattle farmers from their study. Contrarily, Rehman et al. (2013) found that access to agricultural information was not influenced by age.

A positive correlation (0.256) existed between level of education and total information score $(\mathrm{p}<0.05)$. Rehman et al. (2013) and Elias et al. (2013) reported a highly significant association between education and information, whereby higher levels of education were beneficial for increased access to useful information sources. The number of livestock owned (0.067) as well as the farming experience of respondents $(0.183)$ were positively correlated to total information 
scores at $\mathrm{p}<0.01$ and $\mathrm{p}<0.05$ levels of significance respectively. Herd size was reported to be positively correlated to information needs by Singh et al. (2016), which aligns with the finding by Mittal and Mehar (2016) that farm size influences farmers behavior in selecting different information sources. Kavithaa et al. (2014) noted that farming experience influenced information seeking behavior. These imply that farmers with large numbers of livestock and farming experience sought more information and from diverse sources.

Furthermore, the number of extension visits (0.002) was positively correlated to total information scores $(\mathrm{p}<0.05)$ in this study. The finding agrees with many others showing the importance of extension officials in the provision of relevant information to farmers. However, Popoola et al. (2020) reported the poor contribution by extension officials towards farmers' climate information, while Crawford et al. (2015) submitted that the use of extension was the least effective tool for information sourcing among organic farmers. These divergent views regarding the contribution of extension services to farmer's information needs may arise from differences in delivery methods and objectives (Nwafor \& Nwafor, 2020), which affects the effectiveness of public extension delivery in various countries.

Household size was not significant in the total information score of respondents, and this might be a result of the nature of information sought by respondents. Family members might not be technically proficient in matters related to livestock diseases and control measures. However, Onuekwusi and Atasie (2013) as well as Koskei (2012), reported the significant influence of household size for accessing information and use of information sources. Income, access to financial services and cooperative membership did not correlate with respondents total information score. Nonetheless, Sakib et al. (2015) reported that income had a positive and significant relationship with the use of information sources. Tey et al. (2018) also submitted that access to credit improved farmers' access to different information sources, which Yaseen et al. (2018) admitted could sometimes be very costly. Brhane et al. (2017) reported the failure of cooperatives in providing needed information to farmers from their study, which contradicts the assumption by Acheampong et al. (2013) that cooperatives were an effective channel of communication to farmers. While membership of a cooperative increases awareness of information sources and availability (Babu et al., 2012), our finding suggests that cooperatives within the study area were probably not as effective as required, or respondents were not active members.

Predictably, the frequency of information contacts (0.214) and the perceived usefulness of information (0.252) were positively correlated with respondents total information scores at the $\mathrm{p}<0.05$ and $\mathrm{p}<0.01$ levels respectively. Pandit et al. (2019) also utilized the frequency of contacts and usefulness of information to obtain total information scores for comparison among farmers in their study. These variables jointly determine the direction and magnitude of the total information scores. It also agrees with the finding by Okwoche et al. (2012) of a significant relationship between information sources and information utilization. The two variables have shown that the use of any information source during the occurrence of a livestock disease outbreak, depends on its perceived usefulness to the livestock farmer.

\section{Conclusion}

The study set out to examine communication networks used by farmers during a livestock disease outbreak, by exploring their primary information sources and the perceived usefulness of these 
sources. The total information scores were obtained and used to categorize farmers into groups based on their score. Socio-economic characteristics of the livestock farmers were then correlated with their total information scores to determine the existence of any association between personal features and frequent information-contacts perceived useful for obtaining livestock-health related information.

Our findings amplify the importance of inter-personal contacts for successful information dissemination, especially livestock farmers' reliance on their peers. It includes the need for adequate extension coverage and regular visits to livestock farmers by extension officials especially livestock technicians and veterinarians. Effective farmer cooperatives providing requisite information to its members appears to be lacking, while mass media sources such as radio and television were not perceived as useful sources of information during the disease outbreak by livestock farmers.

It is recommended that extension contacts be intensified during a disease outbreak, and mass media be utilized purposefully to disseminate livestock-health information targeted at rural farmers. These impersonal sources of information should be supported by extension communication practitioners to increase coverage and effectiveness. Therefore, extension officials as well as policy makers have a key role to play in this regard. Community awareness and education activities will be helpful to improve knowledge of livestock diseases among farmers and their family members.

While this study contributes to the understanding of livestock-health information sources used by smallholder livestock farmers, it enunciates an urgent need to strengthen information dissemination through mass media sources in the area.

\section{References}

Acheampong, L.D., Frimpong, B.N., Adu-Appiah, A., Asante, B.O. and Asante, M.D. (2017). Assessing the Information Seeking Behaviour and Utilization of Rice Farmers in the Ejisu-Juaben Municipality of Ashanti Region of Ghana. Agriculture and Food Security 6, 38(2017). https://doi.org/10.1186/s40066-017-0114-8.

Adamides, G. and Stylianou, A. (2018). Evaluation of the Radio as an Agricultural Information Sources in Rural Areas. Journal of Agricultural and Food Information, 19(4): 362-376.

Adisa, R.S. (2015). Livestock Extension Practice and Competence among Agricultural Extension Agents in North-Central Nigeria. South African Journal of Agricultural Extension, 43(1): 12-21.

Aidoo, D.C. and Freeman, C.K. (2016). Agricultural Informational Flow in Informal Communication Networks of Farmers in Ghana. Journal of Development and Communications Study, 4(2): 443-453.

Ani, A.O., Umunakwe, P.C., Ejiogu-Okereke, E.N., Nwakwasi, R.N. and Aja, A.O. (2015). Utilization of Mass Media among Farmers in Ikwerre Local Government Area of Rivers State, Nigeria. IOSR Journal of Agriculture and Veterinary Science, 8(7): 41-47.

Babu, S.C., Gladenning, C.J., Asenso-Okyere, K. and Givindarajan, S.K. (2012). Farmer's Information Needs and Search Behaviors: Case Study in Tamil Nadu. IFPRI Discussion Paper 01165, March 2012. International Food Policy Research Institute. 
Balan, K.C. and Norman, S.J. (2012). Community Radio- Participatory Communication Tool for Rural Women Development. International Research Journal of Social Sciences, 1(1): 19-22.

BFAP (2019). Contextualising the 2019 African Swine Fever outbreak in South Africa. Bureau for Agricultural Policy \& South African Pork Producers Organization. September 2019. Available at https://sappo.org/PDF/Media/bfapnuut.pdf.

Borgatti, S.P. and Halgin, D.S. (2011). On Network Theory. Organisation Science, 22(5): 1168-81.

Brhane, G., Mammo, Y. and Negusse, G. (2017). Sources of Information and Information-Seeking Behavior of Smallholder Farmers of Tanqa Abergelle Wereda, Central Zone of Tigray, Ethiopia. Journal of Agricultural Extension and Rural Development, 9(4): 47-52.

Casey-Bryars, M., Reeve, R., Bastola, U. et al. Waves of endemic foot-and-mouth disease in eastern Africa suggest feasibility of proactive vaccination approaches. Nature, Ecology and Evolution 2, 1449-1457 (2018). https://doi.org/10.1038/s41559-018-0636-x

Chikaire, J., Nnadi, F.N. and Ejiogu-Okereke, N. (2011). The Importance of Improved Extension Linkages in Sustainable Livestock Production in Sub-Saharan Africa. Continental Journal of Animal and Veterinary Research, 3(2): 7-15.

Crawford, C., Grossman, J., Warren, S. and Cubbage, F. (2015). Grower Communication Networks: Information Sources for Organic Farmers. Journal of Extension, 53(3), JOE_v53_3a9.pdf

Demiryurek, K. (2010). Information Systems and Communication Networks for Agriculture and Rural People. Agricultural Economics (Czech), 56(5): 209-214.

Department of Agriculture Forestry and Fisheries, (DAFF). Abstract of Agricultural Statistics; Department of Agriculture, Forestry and Fisheries: Pretoria, South Africa, 2018.

Elias, A., Nohmi, M., Yasunobu, K., and Ishida, A. (2013). Effect of agricultural extension programme on smallholders' farm productivity: Evidence from three peasant associations in the highlands of Ethiopia. Journal of Agricultural Science, 5(8), 1916- 9752.

FAO, 2019. Protecting people and animals from disease threats. http://www.fao.org/3/i8747en/I8747EN.pdf

Fori, J. and Etter, E. (2016). Transmission of foot and mouth disease at the wildlife/livestock interface of the Kruger National Park, South Africa: Can the risk be mitigated? Preventive Veterinary Medicine, Volume 126, 1 April 2016, Pages 19-29.

Freeman, K. and Mubichi, F. (2017). ICT Use by Smallholders in Rural Mozambique: A Case Study of Two Villages in Central Mozambique. Journal of Rural Social Sciences, 32(2): 1-19.

Girma, H., Pittchar, J., Khan, Z. and Ochatum, N. (2017). Perceived Preference of Radio as Agricultural Information Source among Smallholder Farmers in Uganda. International Journal of Agricultural Extension, 5(3): 119-130.

Goni, S., Skenjana, A. and Nyangiwe, N. (2018). The Status of Livestock Production in Communal Farming Areas of the Eastern Cape: A Case of Majaali Community, Peelton. Applied Animal Husbandry and Rural Development, 11(2018): 34-40. 
Jack, K. and Tobias, J. (2017). Seeding Success: Increasing Agricultural Technology Adoption through Information. Growth Brief, December 2017. International Growth Centre.

Javaid, U. (2017). Role of Mass Media in Promoting Agricultural Information among Farmers of District Nankana. Pakistan Journal of Agricultural Sciences, 54(3): 711-715.

Kamau, N.J., Margret, W.N. and Hilary, B.K. (2018). Structural Analysis of Social Networks Revealed by Small Holder Banana Farmers in Muranga County, Kenya. Journal of Agricultural Science and Food Research, 9(2): 221-227.

Katikati, A. and Fourie, J.P. (2019). Improving Management Practices of Emerging Cattle Farmers in Selected Areas of the Eastern Cape Province: The Role of Agricultural Extension. South African Journal of Agricultural Extension, 47(1): 97-102.

Kavithaa, N.V., Rajkumar, N.V. and Sree-Lakshmi, C.M. (2014). Information Seeking Behaviour of Dairy Farmers. International Journal of Science, Environment and Technology, 3(4): 1502-6.

Knight-Jones, T.J., McClaws, M. and Rushton, L. 2016. Foot-and-Mouth Disease Impact on Smallholders - What Do We Know, What Don't We Know and How Can We Find Out More? Transboundary and Emerging Diseases, Vol. 64(4): 1079-1094.

Koskei, R.C. (2012). Access and Use of Information by Smallholder Tea farmers in Bureti District, Kenya. Available at http://41.89.96.81:8080/xmlui/handle/123456789/1223.

Kumar, K.R., Nain, M.S., Singh, R., Chapal, V.P. and Bana, R.S. (2015). Analysis of Farmer's Communication Network and Factors of Knowledge regarding Agro-Meteorological Parameters. Indian Journal of Agricultural Sciences, 85(12): 1592-96.

Lamontagne-Godwin, J., Williams, F.E., Aslam, N., Cardey, S., Dorward, P. and Almas, M. (2018). Gender Difference in Use and Preferences of Agricultural Information Sources in Pakistan. The Journal of Agricultural Education and Extension, 24(5): 419-434.

Liu, W., Sidhu, A., Beacom, A.M. and Valente, T. (2017). Social Network Theory. In: The International Encyclopedia of Media Effects. Eds: Patrick Rossler, Cynthia A. Hoffner, Liesbet van Zooner. Wiley Publishers.

Mdlulwa, N.Z. and Klein, K.K. (2015). Socio-Economic Impacts of Lumpy Skin Disease and Rift Valley Fever on the South African Livestock Economy. Agricultural Research Council. Economic Impact Assessment Studies.

Mittal, S. and Mehar, M. (2016). Socio-economic Factors Affecting Adoption of Modern Information and Communication Technology by Farmers in India: Analysis Using Multivariate Probit Model. The Journal of Agricultural Education and Extension, 22(2): 199-212.

Modirwa, S.M. (2019). Effects of Farmers SocioEconomic Characteristics on Access to Agricultural Information in Ngaka Modiri Molema District of the North West Province. International Journal of Agricultural Extension, 7(1): 1-7.

Motiang, D.M. and Webb, E.C. (2015). Sources of Information for Smallholder Cattle Farmers in Dr. Ruth Segomotsi Mompati District Municipality in the North West Province, South Africa. Applied Animal Husbandry and Rural Development, 8: 26-33. 
Mthi, S., Nyangiwe, N., Menhas, R., Mushunje, A. and Ighodaro, B. (2018). Women's participation in livestock activities under small-scale farming system in the Eastern Cape Province, South Africa. Applied Animal Husbandry and Rural Development, 11(1): 14-21.

Myeni, L., Moeletsi, M., Thavhana, M., Randela, M. and Mokoena, L. (2019). Barriers Affecting Sustainable Agricultural Productivity of Smallholder Farmers in the Eastern Free State of South Africa. Sustainability 2019, 11, 3003; doi:10.3390/su11113003.

Nyberg G, Knutsson P, Ostwald M, Öborn I, Wredle E, Otieno DJ, Mureithi S, Mwangi P, Said MY, Jirström M, Grönvall A. (2015). Enclosures in West Pokot, Kenya: transforming land, livestock and livelihoods in drylands. Pastoralism, 3(1): 1-5.

Nwafor, C.U., Ogundeji, A.A. and Westhuizen, C. (2020). Market Information Needs and SeekingBehavior of Smallholder Livestock Farmers in the Eastern Cape Province, South Africa. Journal of Agricultural Extension, 24(3): 98-114.

Nwafor, C. and Nwafor, I. (2020). A Review of Agricultural Extension and Advisory Services in Sub-Saharan African Countries: Progress with Private Sector Involvement. Preprints 2020, doi:10.20944/preprints202008.0294.v1

Okwoche, V.A., Asogwa, B.C and Obinne, P.C. (2012). Agricultural Information Utilization among Sorghum Farmers in Benue State of Nigeria. European Journal of Scientific Research, 76(2): 198207.

Olajide, B.R. (2011). Assessment of Farmers' Access to Agricultural Information on Selected Food Crops in Iddo District of Oyo State, Nigeria. Journal of Agriculture and Food Information, 12(3): 354-363.

Onuekwusi, G.C. and Atasie, C.M. (2013). Socio-economic Characteristics Affecting Information Source Use among Farmers in Ikwuano Local Government Area of Abia State, Nigeria. Journal of Community Mobilization and Sustainable Development, 6(2): 128-140.

Pandit, S.S., Kuwornu, J.K., Datta, A., Yaseen, M. and Anal, A.K. (2019). Analysis of Marketing Information Sources among Smallholder Vegetable Farmers. International Journal of Vegetable Science, 26(1): 96-105.

Popoola, 0.0., Yusuf, S. and Monde, N. (2020). Information Sources and Constraints to Climate Adaptation amongst Smallholder Farmers in Amathole District Municipality, Eastern Cape Province, South Africa. Sustainability 2020, 12, 5846; doi:10.3390/su12145846.

Pratiwi, A. and Suzuki, A. (2017). Effects of Farmers' Social Networks on Knowledge Acquisition: Lessons from Agricultural Training in Rural Indonesia. Journal of Economic Structures, 6, 8(2017). https://doi.org/10.1186/s40008-017-0069-8

Rehman, F., Rubi, T. and Ismat, D. (2013). Effect of farmers' socioeconomic characteristics on access to agricultural information: Empirical evidence from Pakistan. Journal of Animal and Plant Sciences, 23(1): 324-329.

Ritter, C., Janse, J., Roche, S., Kelton, D.F., Adams, C.L. et al. (2017). Determinants of Farmer's Adoption of Management-based Strategies for Infectious Disease Prevention and Control. Journal of Dairy Science, 100(5): 3329-3347. 
Roberts, L.C. and Fosgate, G.T. (2018). Stakeholder perceptions of foot-and-mouth disease control in South Africa. Preventive Veterinary Medicine, 156(1): 38-48.

Sagor, E. and Becker, D. (2014). Personal Networks and Private Forestry in Minnesota. Journal of Environmental Management, 132: 145-154.

Sakib, H., Afrad, S. and Ali, M. (2015). Information Source Preference of Farmers Regarding Modern Aquaculture Technologies in Bogra District of Bangladesh. International Journal of Agricultural Extension, 3(1): 1-5.

SA News (2019). Campaign Initiated Following African Swine Fever Outbreak. South African Government News Agency. July 2, 2019. Available at https://www.sanews.gov.za/southafrica/campaign-initiated-following-african-swine-fever-outbreak.

Sellnow, T.L., Parker, J.S., Sellnow, D.D., Littlefield, R.S and Helsel, E.M. (2017). Improving Biosecurity through Instructional Crisis Communication: Lessons Learned from the PEDv Outbreak. Journal of Applied Communications, vol. 101, no. 4.

Singh, N., Malhotra, P. and Singh, J. (2016). Information Needs and Seeking Behavior of Dairy Farmers of Punjab. Indian Journal of Dairy Science, 69(1): 98-104.

Tey, Y.S., Brindal, M., Li, E., Gill, G., Bruwer, J., Abdullah, A.M. et al. (2018). Factors Affecting the Selection of Information Sources of Sustainable Agricultural Practices by Malaysian Vegetable Farmers. Journal of Agricultural and Food Information, 19(2): 162-175.

Thumbi, S.M., Njenga, M.K., Marsh, T.L., Noh, S., Otiang, E., Munyua, P., et al. (2015). Linking Human Health and Livestock Health: A "One-Health" Platform for Integrated Analysis of Human Health, Livestock Health, and Economic Welfare in Livestock Dependent Communities. PLoSONE, 10(3): e0120761.doi:10.1371/journal.pone.0120761

Yaseen, M., Ahmad, M.M. and Soni, P. (2018). Farm Households Simultaneous Use of Sources to Access Information on Cotton Crop Production. Journal of Agricultural and Food Information, 19(2): 146-161.

Zougmoré, R., Partey, S., Ouédraogo, M. et al. Toward climate-smart agriculture in West Africa: a review of climate change impacts, adaptation strategies and policy developments for the livestock, fishery and crop production sectors. Agric \& Food Secur 5, 26 (2016). https://doi.org/10.1186/s40066-016-0075-3. 